Article

\title{
A Label Free Colorimetric Assay for the Detection of Active Botulinum Neurotoxin Type A by SNAP-25 Conjugated Colloidal Gold
}

\section{Jennifer Halliwell and Christopher Gwenin *}

School of Chemistry, Bangor University, Bangor, Gwynedd, Wales LL57 2DG, UK;

E-Mail: chu60f@bangor.ac.uk

* Author to whom correspondence should be addressed; E-Mail: c.d.gwenin@bangor.ac.uk; Tel: +44-1248-383-741; Fax: +44-1248-370-528.

Received: 7 June 2013; in revised form: 26 July 2013 / Accepted: 30 July 2013 /

Published: 6 August 2013

\begin{abstract}
Botulinum neurotoxins are one of the most potent toxins known to man. Current methods of detection involve the quantification of the toxin but do not take into account the percentage of the toxin that is active. At present the assay used for monitoring the activity of the toxin is the mouse bioassay, which is lengthy and has ethical issues due to the use of live animals. This report demonstrates a novel assay that utilises the endopeptidase activity of the toxin to detect Botulinum neurotoxin in a pharmaceutical sample. The cleaving of SNAP-25 is monitored via UV-Visible spectroscopy with a limit of detection of $373 \mathrm{fg} / \mathrm{mL}$ and has been further developed into a high throughput method using a microplate reader detecting down to $600 \mathrm{fg} / \mathrm{mL}$ of active toxin. The results show clear differences between the toxin product and the placebo, which contains the pharmaceutical excipients human serum albumin and lactose, showing that the assay detects the active form of the toxin.
\end{abstract}

Keywords: botulinum neurotoxin; SNAP-25; localised surface plasmon resonance; colloidal gold

\section{Introduction}

The method currently used for determining the concentration of toxin in a sample is the mouse bioassay. This assay involves injecting the mice with a sample of the toxin and observing them for 
symptoms of the disease over a period of up to four days [1]. The mouse bioassay is able to detect $10 \mathrm{pg} / \mathrm{mL}$ of the toxin; however, it is very lengthy, expensive and has ethical problems in the use of live animals [2].

There is demand for alternative methods to reduce and replace the use of live animals and many botulinum assays are currently being developed including ELISA and fluorescent endopeptidase assays which outperform the mouse bioassay and takes 1-3 h [3-5]. An assay which outperforms current limits of detection and takes minutes to perform would fit a gap in the market having uses in the pharmaceutical industry for batch quality control, as a point of care clinical sensor in suspect botulism cases as well as in biosecurity applications [6].

Botulinum neurotoxins are zinc dependent endopeptidases which cleave the soluble $N$-ethylmaleimide-sensitive attachment protein receptor (SNARE) proteins [7]. The toxin has a mass of $150 \mathrm{kDa}$ and is split into two domains; the heavy chain $(100 \mathrm{kDa})$ which is responsible for uptake into cells and the catalytic light chain $(50 \mathrm{kDa})$ linked to the heavy chain via a disulfide bond [8]. Due to the paralysing effect of the toxin it is often used in low doses to treat conditions such as cervical dystonia and blepharospasm [9].

This assay utilises colloidal gold to produce a visible colour change on addition of sodium chloride. Colloidal gold has been used to develop a wide range of sensors [10-12]. Specific wavelengths of light excite the conduction electrons on the metal surface causing them to oscillate. This oscillation is known as localised surface plasmon resonance (LSPR) and is responsible for the absorption of certain wavelengths of light producing characteristic UV-visible spectrums with a typical absorption peak occurring at around $520 \mathrm{~nm}$ for colloids with a diameter of 10-50 nm [13]. The nanoparticles in colloidal gold are negatively charged and repel each other and hence remain colloidal in nature and appear red in colour, when salt is added these negative charges are masked and the particles aggregate together [14]. This aggregation causes a decrease in interparticle distance allowing the plasma modes to couple together causing the particles to absorb at a longer wavelength, typically around $700 \mathrm{~nm}$ turning the colloidal solution blue [15]. A protein layer covalently bonded onto the gold surface protects the nanoparticles from the ionic effects of the salt, maintaining the red colour and keeping them in solution [16].

Botulinum neurotoxin A selectively cleaves the SNARE protein SNAP-25 between residues 197-198 [17]. SNAP-25 has four cysteine amino acids located at positions 85, 88, 90 and 92; these residues are used to attach to the neural plasma membrane by undergoing palmitoylation, causing the middle cysteine section to be anchored down and the helix chains pointing away from the surface $[18,19]$. Cysteine is able to form a covalent sulfur-gold bond, therefore, SNAP-25's native cysteine residues can be used to attach the protein to gold nanoparticles [20]. Using SNAP-25's native cysteine allows the protein to be orientated correctly, as it would be in the body, so the toxin is not inhibited from reaching the multiple recognition sites [21]. On the addition of the toxin nine amino acids will be cleaved off the C-terminus of the protein, decreasing the protective layer around the nanoparticles making them more susceptible to the salt turning the solution blue. 


\section{Results and Discussion}

\subsection{Coating of Colloidal Gold}

UV-Visible spectrum of coated and uncoated gold particles were measured before and after salt was added to prove that the SNAP-25 bound with the gold surface (Figure 1).

Figure 1. UV-Visible Spectroscopy showing uncoated (left) and coated (right) gold colloids (GC) and the addition of salt causing aggregation of the uncoated particles and cuvette images showing the visible colour change.
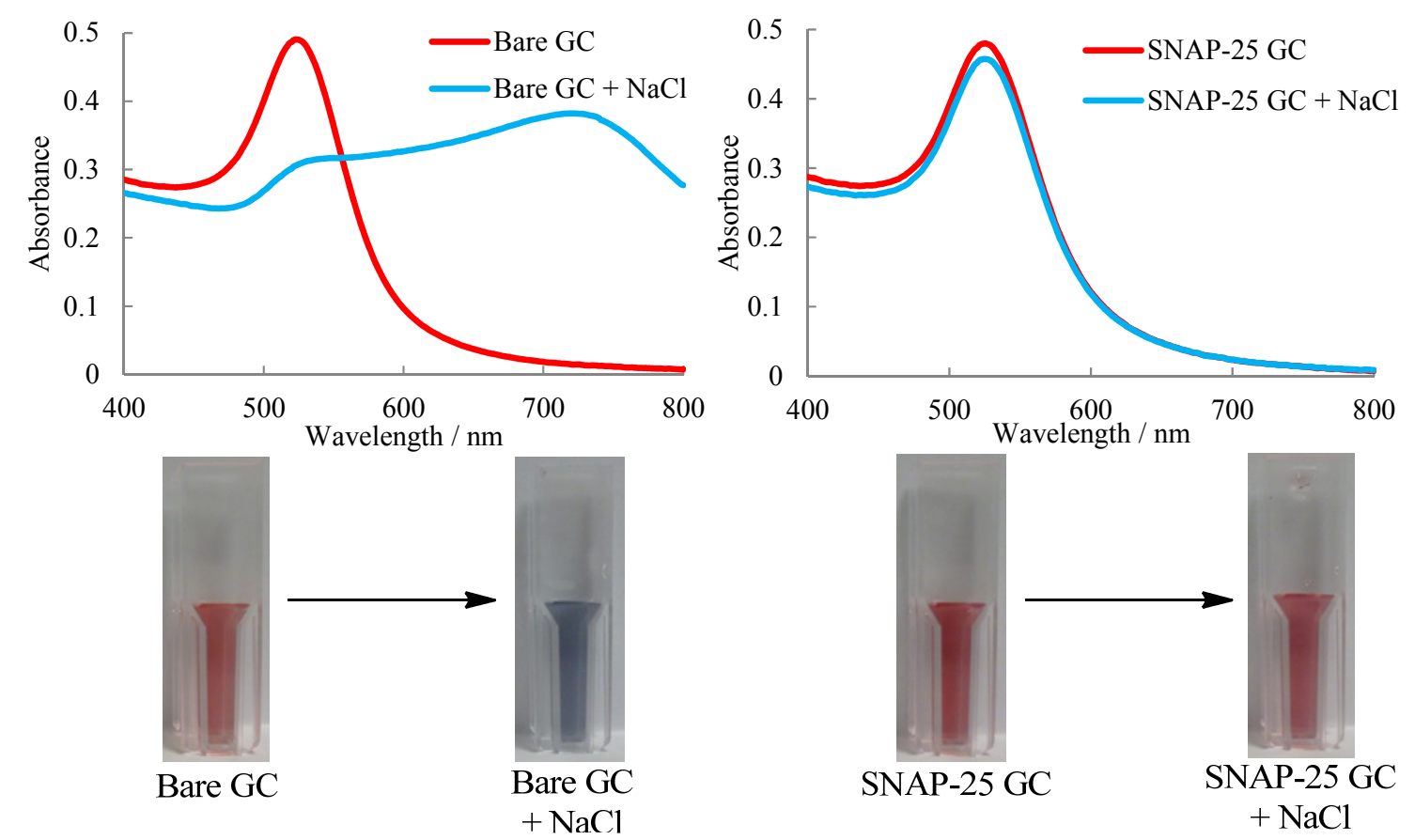

Both uncoated and coated nanoparticles showed plasmon absorbance at around $525 \mathrm{~nm}$ as expected for gold colloids of $20 \mathrm{~nm}$ diameter. On addition of salt the uncoated gold nanoparticles aggregate and turn blue in colour due to the coupling of the localised plasmon resonance increasing the wavelength to around $700 \mathrm{~nm}$. The coated gold nanoparticles show no red shift and only a slight decrease in absorbance at $525 \mathrm{~nm}$ which can be attributed to the dilution of the sample with the salt solution. Thus proving that the particles were sufficiently coated with SNAP-25 as the electrostatic repulsion of the particles was preserved.

The coating of the colloids was repeated with a range of SNAP-25 concentrations and different $\mathrm{pH}$ buffers in the absence of toxin to find the optimum conditions for coating (Figure 2).

Where the absorbance at the two wavelengths showed little change the particles were considered to be stable [22]. The particles were coated with $0.5 \mu \mathrm{g} / \mathrm{mL}$ SNAP-25 for the UV-visible and microplate assay, as, at this concentration, the particles are stable enough so that when the toxin cleaves the nine amino acids of the SNAP-25 they become susceptible to the effects of the salt. If the concentration of the SNAP-25 was too high the particles were too stable and no change in absorbance could be seen. The particles became unstable at low $\mathrm{pH}$ values, as shown in the insert in Figure 2, and it has been 
reported that an alkaline $\mathrm{pH}$ leads to the separation of the toxin from its associated proteins leading to a decrease in endopeptidase activity; hence a $\mathrm{pH}$ of 8 was chosen for this data set [23].

Figure 2. Difference in change in absorbance at 630 and $525 \mathrm{~nm}$ on addition of salt with concentration of SNAP-25. (Insert) surface covered with $0.5 \mu \mathrm{g} / \mathrm{mL}$ of SNAP-25 at different $\mathrm{pH}$ values. Errors calculated to $\pm 1 \mathrm{SD}$.

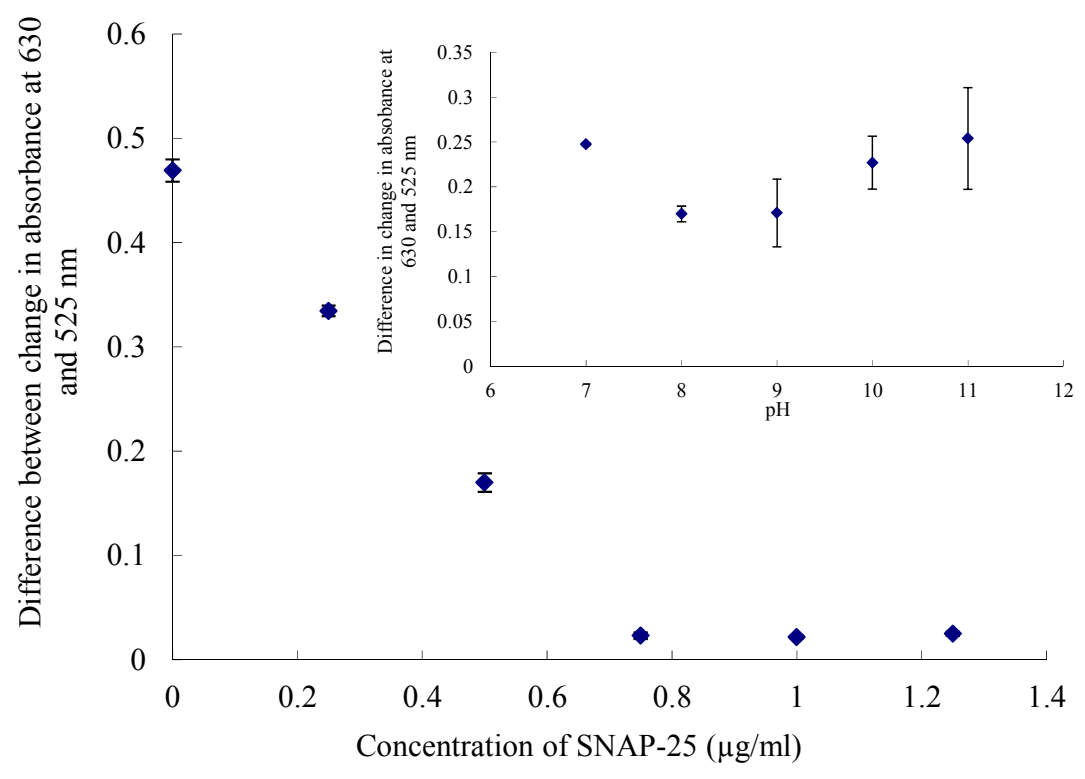

\subsection{SDS-PAGE}

The toxin and SNAP-25 mixture was loaded into the left hand lane with SNAP-25 alone in the right. As there is only $4.35 \mathrm{ng}$ of toxin in Dysport ${ }^{\circledR}$ it does not appear on the gel; however a large band appears at $67 \mathrm{kDa}$ which is the HSA in the toxin product. The lane on the left shows two bands around $25 \mathrm{kDa}$ which correspond to the whole and cleaved SNAP-25; as it is only reduced by $1 \mathrm{kDa}$ it can be difficult to see the two separate bands. However when compared to the SNAP-25 which has not been incubated in the right hand lane the two bands are obvious. SDS-PAGE was used to confirm that the SNAP-25 substrate used in the assay is cleaved by the toxin (Figure 3).

Figure 3. SDS-PAGE gel showing cleaved and whole SNAP-25.

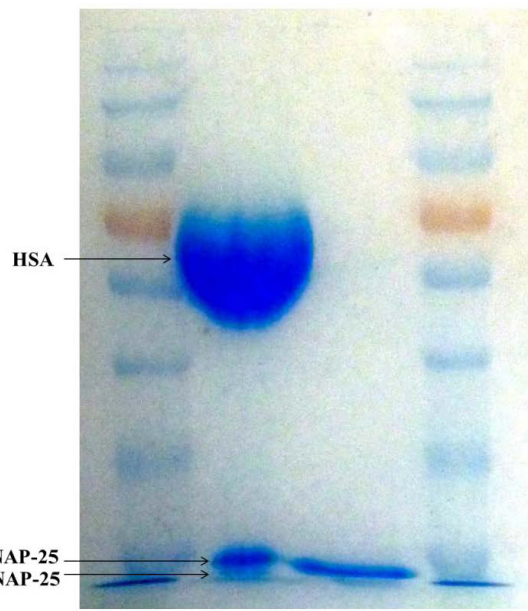




\subsection{UV-Visible Spectroscopy Assay}

Once the optimum conditions for the coating of the particles and the $\mathrm{pH}$ of the buffer was determined the assay was performed using UV-visible spectroscopy to measure the change in absorbance. A typical spectrum is shown in Figure 4.

Figure 4. UV-Visible Spectrum of SNAP-25 coated gold colloids (SGC) incubated with $1 \mathrm{pg} / \mathrm{mL}$ botulinum neurotoxin before $\mathrm{NaCl}$ was added and incubated for five minutes.

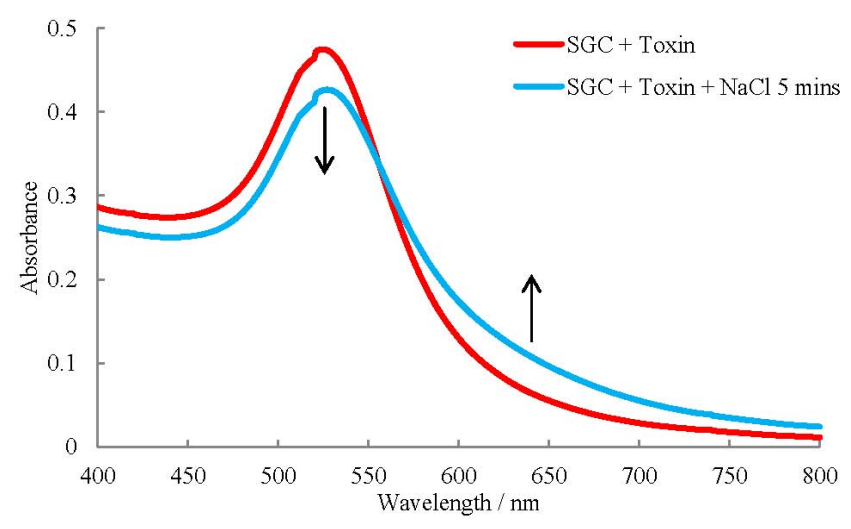

The spectra for the coated particles with toxin before and after the addition of $\mathrm{NaCl}$ show no change in absorbance. After incubating with $\mathrm{NaCl}$ for five minutes there is a decrease in absorbance predominantly at 500-550 $\mathrm{nm}$ and an increase at around 575-800 $\mathrm{nm}$ with the greatest changes occurring at 525 and $630 \mathrm{~nm}$. These results are remarkable considering only 9 amino acids are cleaved off SNAP-25 and $1 \mu \mathrm{L}$ of sample used. Low sample volumes are used due to the regeneration of the toxins active site after a SNAP-25 cut allowing it to cleave multiple SNAP-25 molecules [24].

A range of toxin concentrations and the placebo samples were measured in triplicate with the volume of sample added remaining consistent. The change in absorbance's at $630 \mathrm{~nm}$ and at $525 \mathrm{~nm}$ were calculated then the differences between these two figures used to produce a correlation graph; Figure 5.

The graph shows good correlation for the toxin samples over a range of $250-1500 \mathrm{fg} / \mathrm{mL}$, with the results plateauing at the upper and lower limit, with a calculated limit of detection of $373 \mathrm{fg} / \mathrm{mL}$ [25]. The denatured sample, as prepared in Section 3.2, and the placebo, human serum albumin (125 $\mu \mathrm{g})$ and lactose $(2.5 \mathrm{mg})$, which are the excipients of the Dysport ${ }^{\circledR}$ product supplied by IPSEN, showed a lower response at 0.0242 and 0.0236 respectively. This illustrates that the excipients do not cause false positive results and the assay is detecting active toxin within the range tested. This assay is more sensitive than the mouse bioassay and much quicker with each sample only taking $10 \mathrm{~min}$ for analysis. 
Figure 5. Correlation graph showing difference in change in absorbance at 630 and $525 \mathrm{~nm}$ for a range of Botulinum Neurotoxin concentrations using the UV-Visible Spectrometer. Errors calculated to $\pm 1 \mathrm{SD}$.

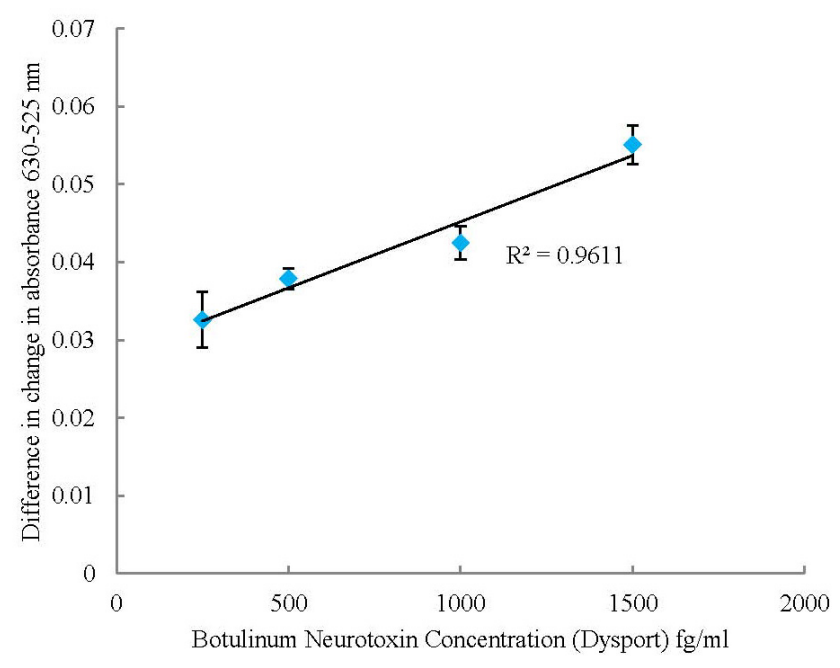

\subsection{Microplate Assay}

The assay was repeated using 96 well plates again with each sample being analysed in triplicate. The change in absorbance's at $630 \mathrm{~nm}$ and $492 \mathrm{~nm}$ were calculated then the difference between these two figures used to produce the graph; Figure 6.

Figure 6. Correlation graph showing difference in change in absorbance at 630 and $492 \mathrm{~nm}$ for a range of Botulinum Neurotoxin concentrations using the microplate reader. Errors calculated to $\pm 1 \mathrm{SD}$.

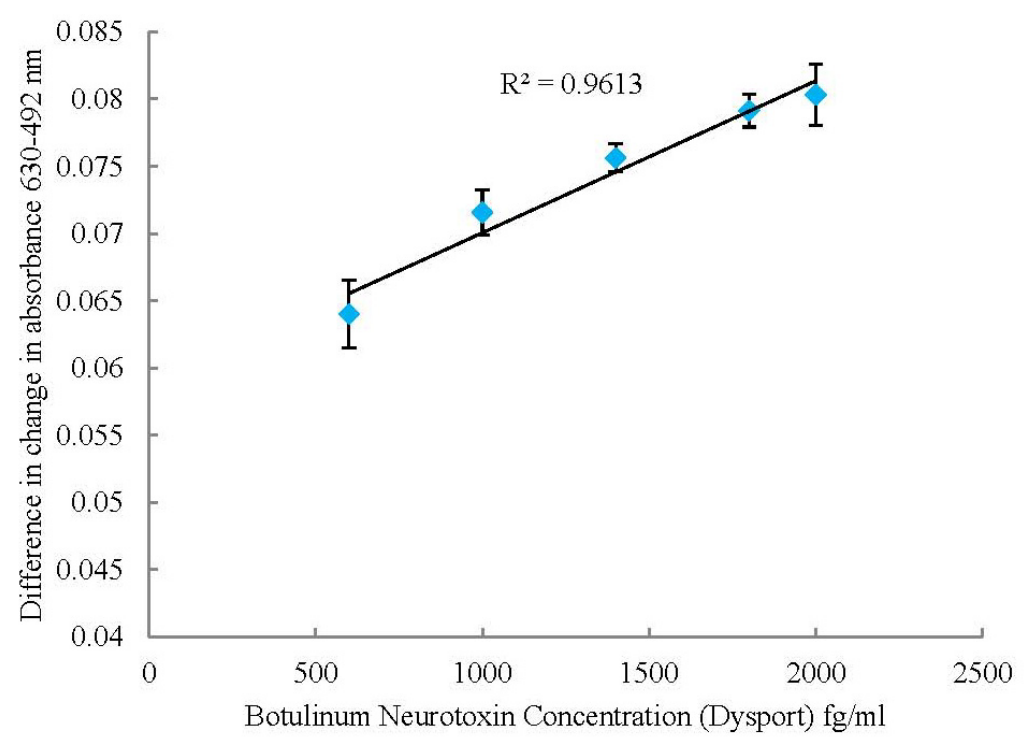

The absorbance was measured at $492 \mathrm{~nm}$ rather than $525 \mathrm{~nm}$ as in the UV-visible spectroscopy assay due to the availability of wavelength filters for the microplate reader. This changed the detection range to $600-2000 \mathrm{fg} / \mathrm{mL}$ with a calculated limit of detection of $278 \mathrm{fg} / \mathrm{mL}$, again with the results plateauing at the upper and lower limits. The linear detection range was slightly higher than the 
UV-visible spectrometry but still lower than the mouse bioassay. Using the microplate reader allows a much higher throughput; taking seven minutes for 96 samples. The response for the placebo and denatured toxin samples were again much lower than the toxin samples at 0.0523 and 0.0572 respectively showing this assay is detecting the active form of the toxin.

\section{Methods and Materials}

Colloidal gold ( $20 \mathrm{~nm}, 7 \times 10^{11}$ particles $/ \mathrm{mL}$ ) was purchased from BBInternational, SNAP-25 was from Stratech Scientific, Monopotassium phosphate, Dipotassium phosphate, Zinc Chloride, Dithiothreitol, Tween-20 and HEPES were purchased from Sigma Aldrich and Sodium Chloride was bought from Fisher Scientific. Dysport ${ }^{\circledR}$ samples containing lyophilised Clostridium Botulinum Type A toxin-haemaggluttinin complex $(4.35 \mathrm{ng})$, human serum albumin $(125 \mu \mathrm{g})$ and lactose $(2.5 \mathrm{mg}) \mathrm{and}$ placebos containing the excipients from Dysport ${ }^{\circledR}$ were supplied by IPSEN Biopharm. Water was purified and had a nominal resistivity of $18 \mathrm{M} \Omega \mathrm{cm}$ at $25^{\circ} \mathrm{C}$.

\subsection{Coating Colloidal Gold}

The colloidal gold solution was mixed in a 1:1 ratio with phosphate buffer $(10 \mathrm{mM}, \mathrm{pH} 8)$ and placed on an orbital shaker at $37^{\circ} \mathrm{C}$ to equilibrate. SNAP-25 solution was incubated at $37{ }^{\circ} \mathrm{C}$ before being added $(500 \mathrm{ng} / \mathrm{mL})$ to the gold solution and left on the shaker overnight. All solutions were kept at $37^{\circ} \mathrm{C}$ prior to use, all incubations were also performed at this temperature.

The concentration of SNAP-25 and the $\mathrm{pH}$ of the buffer were determined by coating colloids in a range of concentrations in buffers of varying $\mathrm{pH}$. Phosphate buffer was used for $\mathrm{pH} 7-8$ and a sodium carbonate/bicarbonate buffer was used for $\mathrm{pH} 9-11$. Aliquots of these solutions $(960 \mu \mathrm{L})$ were transferred to cuvettes and the absorbance from 400 to $800 \mathrm{~nm}$ measured. $\mathrm{NaCl}(4 \mathrm{M}, 40 \mu \mathrm{L})$ was then added, incubated for $5 \mathrm{~min}$ and the absorbance re-measured.

\subsection{Pre-treatment of Samples}

Before analysis samples were diluted in a digestion buffer $(20 \mu \mathrm{L})$ of $\mathrm{ZnCl}_{2}(0.5 \mathrm{mM})$, Dithiothreitol $(2 \mathrm{mM})$, HEPES $(50 \mathrm{mM})$ and Tween-20 (0.05\%) at pH 7.4 and incubated for an hour at $37{ }^{\circ} \mathrm{C}$ [26]. This reduced any toxin present in the sample to the active form by separating the catalytic light chain from the heavy chain.

Denatured samples were produced by incubating Dysport ${ }^{\circledR}$ samples at $95{ }^{\circ} \mathrm{C}$ for $15 \mathrm{~min}$ [27].

\section{3. $S D S-P A G E$}

Toxin was pre-treated before SNAP-25 was added to a final concentration of $3.3 \mu \mathrm{g} / \mu \mathrm{L}$ and incubated at $37{ }^{\circ} \mathrm{C}$ for an hour. The toxin/SNAP-25 and SNAP-25 sample were added to a $10 \%$ SDS-PAGE gel and run at $100 \mathrm{~V}$.

\subsection{UV-Visible Spectroscopy Assay}

The SNAP-25 gold conjugate $(960 \mu \mathrm{L})$ was added to a cuvette and the absorbance read from 400-800 nm using a Jasco V-550 UV-Visible Spectrometer. The sample $(1 \mu \mathrm{L})$ was then added and 
the absorbance re-measured the solution was then allowed to incubate for $5 \mathrm{~min} . \mathrm{NaCl}(4 \mathrm{M}$, $40 \mu \mathrm{L}$ ) was added and the absorbance measurement repeated. The solution was left to incubate for a further $5 \mathrm{~min}$ before a final reading was taken. All measurements were recorded against a reference sample of phosphate buffer with the background absorbance removed.

\subsection{Microplate Assay}

Samples $(0.5 \mu \mathrm{L})$ were added to the wells of a microliter plate and SNAP-25 gold conjugate $(374 \mu \mathrm{L})$ added to each well before the absorbance at 492 and $630 \mathrm{~nm}$ was measured using a Labtech LT-4000 microplate reader. The plate was then incubated for $2 \mathrm{~min}$ before $\mathrm{NaCl}$ was added ( $4 \mathrm{M}$, $15 \mu \mathrm{L}$ ) and incubated for $5 \mathrm{~min}$. before the absorbance was re-measured.

\section{Conclusions}

Many assays currently being developed, such as the ELISA assay, only detect the presence of the toxin and are unable to measure the proteolytic activity, so do not differentiate between active and denatured toxin [28]. By measuring the colour change after the toxin has cleaved the SNAP-25, our assay detects only active botulinum neurotoxin making it highly useful for the pharmaceutical industry. This is particularly relevant when the low detection limit of $250 \mathrm{fg} / \mathrm{mL}$ is considered, which is lower than the mouse bioassay and requires only $0.5-1 \mu \mathrm{L}$ per sample, making it safer and cheaper to be run. These assays detect much lower amounts of toxin than the amount typically contained in pharmaceutical products, around $4 \mathrm{ng}$, meaning that a set of serial dilutions would need to be performed to analyse the products correctly. This is simple to perform and would only add a few minutes onto the overall analysis time.

This assay may also be used as a point-of-care sensor and as a screening step in the food industry with the inclusion of sample purification steps such as immunochromatography and centrifugation $[29,30]$.

With the transfer of the assay onto a microplate reader 96, samples can be processed in seven minutes allowing for high throughput analysis. This also leads to the possibility of automating the assay and using plates with more wells, further increasing output.

SNAP-25 is cleaved by serotypes A, C and E, as stated in the literature. By using SNAP-25 as the substrate this assay currently can only detect these serotypes [31]. This assay will be further developed to detect other serotypes by modifying the gold surface with VAMP and Syntaxin through the sulfur on the methionine side chain [32].

Many botulinum neurotoxin assays do not advance from the development stage due to interference from excipients commonly found in toxin drug products such as HSA [33]. This assay has been developed using Dysport ${ }^{\circledR}$ and a placebo which contains HSA and lactose. The results show good correlation and the placebo has a much lower response proving this assay is not affected by the excipients [34]. 


\section{Acknowledgments}

The authors would like to thank IPSEN Biopharm and the Knowledge Economy Skills Scholarship (KESS) for funding the project and IPSEN Biopharm for supplying samples of Dysport ${ }^{\circledR}$ and placebo.

\section{Conflict of Interest}

The authors declare no conflict of interest.

\section{References}

1. Pellett, S.; Tepp, W.H.; Toth, S.I.; Johnson, E.A. Comparison of the primary rat spinal cord cell (RSC) assay and the mouse bioassay for botulinum neurotoxin type A potency determination. J. Pharmacol. Toxicol. Method. 2010, 61, 304-310.

2. Rasooly, R.; Do, P.M. Development of an in vitro activity assay as an alternative to the mouse bioassay for Clostridium botulinum neurotoxin type A. Appl. Environ. Microbiol. 2008, 74, 4309-4313.

3. Pires-Alves, M.; Ho, M.; Aberle, K.K.; Janda, K.D.; Wilson, B.A. Tandem fluorescent proteins as enhanced FRET-based substrates for botulinum neurotoxin activity. Toxicon 2009, 53, 392-399.

4. Moorthy, J.; Mensing, G.A.; Kim, D.; Mohanty, S.; Eddington, D.T.; Tepp, W.H.; Johnson, E.A.; Beebe, D.J. Microfluidic tectonics platform: A colorimetric, disposable botulinum toxin enzyme-linked immunosorbent assay system. Electrophoresis 2004, 25, 1705-1713.

5. Ching, K.H.; Lin, A.; McGarvey, J.A.; Stanker, L.H.; Hnasko, R. Rapid and selective detection of botulinum neurotoxin serotype-A and -B with a single immunochromatographic test strip. J. Immunol. Method. 2012, 380, 23-29.

6. Katona, P. Botulinum toxin: Therapeutic agent to cosmetic enhancement to lethal biothreat. Anaerobe 2012, 18, 240-243.

7. Kukreja, R.V.; Singh, B.R. Comparative role of neurotoxin-associated proteins in the structural stability and endopeptidase activity of botulinum neurotoxin complex types $\mathrm{A}$ and $\mathrm{E}$. Biochemistry 2007, 46, 14316-14324.

8. Montal, M. Botulinum neurotoxin: A marvel of protein design. Annu. Rev. Biochem. 2010, 79, 591-617.

9. Chen, S. Clinical uses of botulinum neurotoxins: Current indications, limitations and future developments. Toxins 2012, 4, 913-939.

10. Dasary, S.S.R.; Singh, A.K.; Senapati, D.; Yu, H.; Ray, P.C. Gold nanoparticle based label-free SERS probe for ultrasensitive and selective detection of trinitrotoluene. J. Am. Chem. Soc. 2009, 131, 13806-13812.

11. Bajaj, A.; Miranda, O.R.; Kim, I.-B.; Phillips, R.L.; Jerry, D.J.; Bunz, U.H.F.; Rotello, V.M. Detection and differentiation of normal, cancerous, and metastatic cells using nanoparticle-polymer sensor arrays. Proc. Nat. Acad. Sci. USA 2009, 106, 10912-10916.

12. Xu, H.; Mao, X.; Zeng, Q.; Wang, S.; Kawde, A.-N.; Liu, G. Aptamer-functionalized gold nanoparticles as probes in a dry-reagent strip biosensor for protein analysis. Anal. Chem. 2009, $81,669-675$. 
13. Zhao, W.; Brook, M.A.; Li, Y. Design of gold nanoparticle-based colorimetric biosensing assays. Chembiochem 2008, 9, 2363-2371.

14. Li, L.; Li, B.; Qi, Y.; Jin, Y. Label-free aptamer-based colorimetric detection of mercury ions in aqueous media using unmodified gold nanoparticles as colorimetric probe. Anal. Bioanal. Chem. 2009, 393, 2051-2057.

15. Wang, G.; Sun, W. Optical limiting of gold nanoparticle aggregates induced by electrolytes. J. Phys. Chem. B 2006, 110, 20901-20905.

16. Dominguez-Medina, S.; Blankenburg, J.; Olson, J.; Landes, C.F.; Link, S. Adsorption of a protein monolayer via hydrophobic interactions prevents nanoparticle aggregation under harsh environmental conditions. ACS Sustain. Chem. Eng. 2013, 1, 833-842.

17. Chen, S.; Barbieri, J.T. Association of botulinum neurotoxin serotype a light chain with plasma membrane-bound SNAP-25. J. Biol. Chem. 2011, 286, 15067-15072.

18. Greaves, J.; Chamberlain, L.H. Differential palmitoylation regulates intracellular patterning of SNAP25. J. Cell Sci. 2011, 124, 1351-1360.

19. Breidenbach, M.A.; Brunger, A.T. Substrate recognition strategy for botulinum neurotoxin serotype A. Nature 2004, 432, 925-929.

20. Gwenin, C.D.; Kalaji, M.; Williams, P.A.; Jones, R.M. The orientationally controlled assembly of genetically modified enzymes in an amperometric biosensor. Biosens. Bioelectron. 2007, 22, 2869-2875.

21. Chen, S.; Barbieri, J.T. Unique substrate recognition by botulinum neurotoxins serotypes A and E. J. Biol. Chem. 2006, 281, 10906-10911.

22. Zhang, F.; Skoda, M.W.A.; Jacobs, R.M.J.; Dressen, D.G.; Martin, R.A.; Martin, C.M.; Clark, G.F.; Lamkemeyer, T.; Schreiber, F. Gold nanoparticles decorated with oligo(ethylene glycol) thiols: Enhanced hofmeister effects in colloid-protein mixtures. J. Phys. Chem. C 2009, 113, 4839-4847.

23. Cai, S.O.; Sarkar, H.K.; Singh, B.R. Enhancement of the endopeptidase activity of botulinum neurotoxin by its associated proteins and dithiothreitol. Biochemistry 1999, 38, 6903-6910.

24. Chen, S.; Kim, J.-J.P.; Barbieri, J.T. Mechanism of substrate recognition by botulinum neurotoxin serotype A. J. Biol. Chem. 2007, 282, 9621-9627.

25. Armbruster, D.A.; Pry, T. Limit of blank, limit of detection and limit of quantitation. Clin. Biochem. Rev. 2008, 29, S49-S52.

26. Hunt, T.; Rupp, D.; Shimizu, G.; Tam, K.; Weidler, J.; Xie, J. Characterization of SNARE cleavage products generated by formulated botulinum neurotoxin type-a drug products. Toxins 2010, 2, 2198-2212.

27. Davis, L.E. Botulism. Curr. Treat Opt. Neurol. 2003, 5, 23-31.

28. Liu, Y.Y.B.; Rigsby, P.; Sesardic, D.; Marks, J.D.; Jones, R.G.A. A functional dual-coated (FDC) microtiter plate method to replace the botulinum toxin LD50 test. Anal. Biochem. 2012, 425, $28-35$.

29. Dunning, F.M.; Ruge, D.R.; Piazza, T.M.; Stanker, L.H.; Zeytin, F.N.; Tucker, W.C. Detection of botulinum neurotoxin serotype $\mathrm{A}, \mathrm{B}$, and $\mathrm{F}$ proteolytic activity in complex matrices with picomolar to femtomolar sensitivity. Appl. Environ. Microbiol. 2012, 78, 7687-7697. 
30. Moser, A.C.; Hage, D.S. Immunoaffinity chromatography: An introduction to applications and recent developments. Bioanalysis 2010, 2, 769-790.

31. Lebeda, F.J.; Cer, R.Z.; Mudunuri, U.; Stephens, R.; Singh, B.R.; Adler, M. The zinc-dependent protease activity of the botulinum neurotoxins. Toxins 2010, 2, 978-997.

32. Strong, A.E.; Moore, B.D. Self-assembling monolayers of helical oligopeptides on gold with applications in molecular electronics. J. Mater. Chem. 1999, 9, 1097-1105.

33. Jones, R.G.A.; Liu, Y.; Halls, C.; Thorpe, S.J.; Longstaff, C.; Matejtschuk, P.; Sesardic, D. Release of proteolytic activity following reduction in therapeutic human serum albumin containing products: Detection with a new neoepitope endopeptidase immunoassay. J. Pharmaceut. Biomed. Anal. 2011, 54, 74-80.

34. Gwenin, C.D.; Halliwell, J. Detection of Botulinum Toxin. UK patent application No. 1310090.4, May 2013.

(C) 2013 by the authors; licensee MDPI, Basel, Switzerland. This article is an open access article distributed under the terms and conditions of the Creative Commons Attribution license (http://creativecommons.org/licenses/by/3.0/). 